\title{
Propofol affects the biological behavior of ovarian cancer SKOV3 cells via ERK1/2-MMP-2/9 signaling pathway
}

\author{
Ruchang Yin ${ }^{1}$, Chunyan Zhang ${ }^{1}$, Aizhi Gen ${ }^{1}$, Yanxiao $\mathrm{Li}^{1}$, Hailei Yang ${ }^{1}$, Xin \\ $\mathrm{Tian}^{1}$, Yasong $\mathrm{Chi}^{2 *}$ \\ ${ }^{1}$ Department of Gynaecology, The Second Liaocheng People's Hospital, Liaocheng, ${ }^{2}$ Liaocheng Second People's Hospital \\ Huamei Branch Gynecology Xinhua Road and Huamei Road Intersection, Linqing City, Shandong Province, China
}

*For correspondence: Email: psi62p@163.com

\begin{abstract}
Purpose: To investigate the effect of propofol on the biological behavior of ovarian cancer SKOV3 cells, and the mechanism of action involved.

Methods: SKOV3 cells cultured in vitro were randomly divided into control group, fat emulsion group, low-dose propofol group (LDPG, $25 \mu \mathrm{mol} / \mathrm{L})$, medium-dose propofol group (MDPG) (50 $\mu \mathrm{mol} / \mathrm{L})$ and high-dose propofol group (HDPG) (100 $\mu$ mol/L). Apoptosis was determined by flow cytometry, while Transwell assay was used to measure the migration and invasion abilities of the cells. The protein levels of ERK1/2, MMP-2, MMP-9 were assayed with Western blotting. Moreover, the cells were transfected with siERK, and the regulatory effect of propofol on ERK1/2-MMP-2/9 signaling pathway was determined.

Results: Apoptosis in HDPG was significantly reduced, relative to MDPG, while migration and invasion were enhanced, relative to MDPG $(p<0.05)$. Moreover, MMP-2, ERK1/2, and MMP-9 proteins were significantly higher in MDPG and HDPG than in control, fat emulsion and LDPGs $(p<0.05)$, and were upregulated in HDPGs, relative to MDPG $(p<0.05)$. In contrast, propofol did not up-regulate these proteins in siRNA-treated cells.

Conclusion: Propofol enhances the migration, proliferation, and invasive ability SKOV3 cells, and upregulates the expressions of MMP-2, ERK1/2, and MMP-9 in these cells, via a mechanism related to the activation of ERK1/2-MMP-2/9 signaling route. These properties provide novel leads for the development of new drugs for ovarian cancer
\end{abstract}

Keywords: Propofol, ERK1/2-MMP-2/9 signal route, Ovarian cancer, Biological behavior

\begin{abstract}
This is an Open Access article that uses a fund-ing model which does not charge readers or their institutions for access and distributed under the terms of the Creative Commons Attribution License (http://creativecommons.org/licenses/by/4.0) and the Budapest Open Access Initiative (http://www.budapestopenaccessinitiative.org/read), which permit unrestricted use, distribution, and reproduction in any medium, provided the original work is properly credited.
\end{abstract}

Tropical Journal of Pharmaceutical Research is indexed by Science Citation Index (SciSearch), Scopus, International Pharmaceutical Abstract, Chemical Abstracts, Embase, Index Copernicus, EBSCO, African Index Medicus, JournalSeek, Journal Citation Reports/Science Edition, Directory of Open Access Journals (DOAJ), African Journal Online, Bioline International, Open-J-Gate and Pharmacy Abstracts

\section{INTRODUCTION}

Ovarian cancer, a malignant reproductive tumor with very high fatality, is usually characterized by metastasis into the pelvic region and abdominal cavity. Due to the deep position of the ovaries in the pelvic cavity and the insidious nature of the disease, more than $70 \%$ of the patients have metastasis at the time of diagnosis [1]. Tumor cell reduction is often used in clinics for treating ovarian cancer, in combination with platinum, paclitaxel and other chemotherapeutic drugs. 
However, most patients experience recurrence within 18 to 28 months, and the 5-year survival is still low, thereby posing a big threat to the lives of patients. In recent years, with progress in combined use of various methods and combined treatments from a variety of disciplines, early diagnosis of ovarian cancer, and the probability of radical operation have significantly increased. A variety of trauma stresses may cause abnormal immune function in the course of surgical treatment, and may lead to organ failure in severe cases. The inhibition of immune function by anesthesia, and the effect on tumor cells can directly affect the survival of patients [4]. At present, there are few clinical studies on the effect of anesthesiology on the biological activity of ovarian cancer.

Propofol is a widely used intravenous anesthetic agent with quick action and rapid metabolism, and is mainly used for anesthesia induction, anesthesia maintenance, and sedation. In addition to sedation, propofol exerts protective effects against damage from free radical injury, ischemia-reperfusion organ injury and nerve injury [5]. Research has indicated that some of anesthetic drugs induce tumor cell metastasis by inhibiting the lethality of natural killer cells [6]. The present study was carried out to investigate the effect of propofol on ovarian cancer SKOV3 cells.

\section{EXPERIMENTAL}

\section{Reagents and materials}

Human ovarian cancer SKOV3 cells were taken from Shanghai Cell Bank, CAS. The RPMI1640 and DMEM were purchased from Gibco Company (US). Fetal calf serum (FCS) was purchased from $\mathrm{BI}$ Company (Israel). Bicinchoninic acid assay (BCA) kits for protein quantitation were products of Pierce Company (US). Sodium dodecyl sulfate (SDS) was purchased from Sigma company (US), while 100 and $75 \%$ alcohol were purchased from Shandong Lierkang Medical Technology Co. Ltd. Assay kits for CCK were obtained from DOJINDO Laboratories (Japan).

An optical microscope was purchased from Nikon Company (Japan). Desktop high-speed centrifuge was supplied by Beijing Jingli Centrifuge Company. Carbon dioxide thermostatic incubator was purchased from SHELDON Company (US). Cell counting instrument and full-automatic enzyme labeling instrument were products of Thermo Company (US). Constant temperature water bath pot (electric) was purchased from Shanghai Xinmiao Medical Device Manufacturing Co. Ltd. Flow cytometer was product of BECKMAN COULTER (Germany). Electronic balance (Auw 120 type) was purchased from Shimadzu Company (Japan).

\section{Cell culture}

Human ovarian cancer SKOV3 cells were reheated at $37{ }^{\circ} \mathrm{C}$ and placed in DMEM medium containing $100 \mathrm{ml}$ PBS buffer and $10 \mathrm{ml} / \mathrm{L}$ penicillin-streptomycin double antibody. Cell culturing was done at $37^{\circ} \mathrm{C}$ at saturated humidity and $5 \% \mathrm{CO}_{2}$. Following cell fusion after 3 to 4 days, the cells were digested and sub-cultured. Cells at logarithmic phase of growth were cultured for 4 to 5 generations. The cultured ovarian cancer SKOV3 cells were randomly divided into control group (without any treatment), fat emulsion group (treated with fat emulsion), LDPG, MDPG and HDPG.

\section{Determination of cell proliferation}

Cell proliferation was measured by CCK-8 assay. Logarithmic growth SKOV3 cells were prepared into cell suspension and inoculated in 96-well plates at a density of $3 \times 10^{3}$ cells per well. Three compound wells and one blank control group were set up for each group, and cultured in an incubator. At 24, 48 and $72 \mathrm{~h}$ of cell growth, cell incubation was done with $100 \mu \mathrm{L}$ of RPMI-1640 complete medium and CCK-8 $(10 \mu \mathrm{L})$ for $1-4 \mathrm{~h}$, after which the OD of each well plate was read at $450 \mathrm{~nm}$ in enzyme labeling instrument.

\section{Apoptotic ability of the cells}

Apoptotic ability of the cells was measured flow cytometrically. The SKOV3 cells at logarithmic phase were inoculated in 24-well plates at a volume of $1 \mathrm{~mL}$ per well for $24 \mathrm{~h}$. Cells of each group were subjected to centrifugation at 1500 rpm for 5 min, and diluted 10 times with binding buffer. After washing with PBS buffer and working solution of binding buffer, the cells were resuspended in $100 \mu \mathrm{L}$ working solution of binding buffer. Then, $1 \mu \mathrm{L}$ of Annexin $V$ was added to each group of cells, and the degree of apoptosis was determined with flow cytometry within $4 \mathrm{~h}$ after mixing.

\section{Cell migration and invasion testing}

Transwell assay was employed to determine cell migratory and invasive potential. The cells were selected from serum-free starvation culture for 12 to $24 \mathrm{~h}$, followed by cell count. Each group of cells was inoculated in the chamber at a 
concentration of $5 \times 10^{4}$ cells per well. After $24 \mathrm{~h}$ of culture, the medium was removed from the chamber and culture plate. Unmigrated cells on the medial and basement membrane of the upper chamber were wiped off, and the cells were fixed, stained and cleaned after air-drying the chamber. Five fields of view were selected for photography using a microscope. Matrigel glue was used for cell invasion experiment. In essence, $50 \mu \mathrm{l}$ of diluted Matrigel glue of BD was spread on the surface of the chamber. Residual liquid in the upper chamber was sucked out, followed by addition of serum-free culture medium, and placing in the incubator for $30 \mathrm{~min}$. The subsequent steps were the same as in the migration experiment.

\section{Assessment of protein expressions of ERK1/2, MMP-2 and MMP-9}

The protein levels of ERK1/2, MMP-2 and MMP9 were determined using Western blot. Cells in logarithmic growth phase were rinsed in precooled PBS buffer and subjected to centrifugation at $5000 \mathrm{rpm}$ for $5 \mathrm{~min}$ at $4^{\circ} \mathrm{C}$. Then, the cells were re-suspended and centrifuged again, followed with lysing with PIPA. Protein was assayed in the lysate using BCA kit. Thereafter, equal amounts of protein were subjected to SDS-PAGE at $90 \mathrm{~V}$, and transferred to polyvinylidene membrane which was then treated with $5 \%$ skim milk powder, followed by rinsing in TBST buffer.

Then, it was incubated with rabbit anti-human ERK polyclonal antibody, rabbit anti-human MMP-2 polyclonal antibody, rabbit anti-human MMP-9 polyclonal antibody, and $\beta$-actin rabbit polyclonal antibody overnight in a horizontal shaking bed at $4^{\circ} \mathrm{C}$. Then, the PVDF membrane was rinsed thrice with TBST buffer, and incubated with IgG-HRP-labeled sheep antirabbit secondary antibody on a shaking bed for 2 h. Thereafter, the membrane was washed thrice using TBST buffer. The PVDF membrane was exposed to a gel imaging system, and the gray values of the bands on the image were determined using analysis software.

\section{Statistical analysis}

Measurement data are expressed as mean \pm SD. Student's $t$-test was used to compare data between two groups, while repeated measurement variance was used for multi-group comparisons. Data analyses were done with SPSS ver. 21 software package. Statistical significance of difference was assumed at $p<$ 0.05 .

\section{RESULTS}

\section{Effect of propofol on proliferation of ovarian cancer SKOV3 cells}

As shown in Table 1, after 24,48 and $72 \mathrm{~h}$ of treatment, the $O D$ value of high-dose propofol group was significantly higher than that of control group, fat emulsion group or LDPG $(p<0.05)$. Moreover, the $O D$ value at each time point in HDPG was markedly higher than that of mediumdose propofol group $(p<0.05)$.

Table 1: Effect of propofol on OD value of ovarian cancer SKOV3 cells

\begin{tabular}{lccc}
\hline Group & $\mathbf{2 4 h}$ & $\mathbf{4 8 h}$ & $\mathbf{7 2 h}$ \\
\hline Control & $1.10 \pm 0.02$ & $1.35 \pm 0.05$ & $2.10 \pm 0.12$ \\
Fat emulsion & $1.11 \pm 0.07$ & $1.30 \pm 0.02$ & $1.99 \pm 0.07$ \\
LDPG & $1.01 \pm 0.02$ & $1.24 \pm 0.07$ & $1.94 \pm 0.09$ \\
MDPG & $1.25 \pm 0.04$ & $1.52 \pm 0.05$ & $2.29 \pm 0.07$ \\
HDPG & $1.46 \pm 0.07^{\circ \#}$ & $1.85 \pm 0.15^{* \#}$ & $2.56 \pm 0.08^{\circ \#}$ \\
\hline$P<0.05$, vs control, fat emulsion group and LDPG; ${ }^{*} p$ \\
$<0.05$, vs MDPG
\end{tabular}

\section{Effect of propofol on apoptosis, and invasive and migratory capacities of ovarian cancer SKOV3 cells}

As shown in Table 2, percentage apoptosis in MDPG and HDPG were significantly lower than those in control, fat emulsion and low-dose propofol groups; and migration and invasion were markedly increased, relative to the other three groups $(p<0.05)$. Percentage apoptosis in HDPG was significantly lower than that in MDPG, and they had higher migration and invasion than medium-dose propofol group $(p<0.05)$.

Table 2: Effect of propofol on apoptosis, invasion and migration of ovarian cancer SKOV3 cells

\begin{tabular}{lccc}
\hline Group & Apoptosis (\%) & Number of cells migrated & Number of invading cells \\
\hline Control & $11.22 \pm 0.23$ & $32.13 \pm 3.15$ & $25.90 \pm 2.51$ \\
Fat emulsion & $11.14 \pm 0.24$ & $37.45 \pm 1.13$ & $27.11 \pm 3.24$ \\
Low dose propofol & $12.11 \pm 0.19$ & $35.22 \pm 2.24$ & $28.33 \pm 2.20$ \\
Medium dose propofol & $9.73 \pm 0.20^{*}$ & $55.32 \pm 3.86^{*}$ & $45.12 \pm 3.75$ \\
High dose propofol & $8.52 \pm 0.21^{\text {\#\# }}$ & $67.45 \pm 3.80^{* \#}$ & $55.56 \pm 3.10^{* \#}$ \\
\hline$P<0.05$, vs control, fat emulsion group and LDPG: ${ }^{*} p<0.05$, vs MDPG
\end{tabular}


Effect of propofol on ERK1/2, MMP-2 and MMP-9 expressions in ovarian cancer SKOV3 cells

Results from Western blotting showed that protein levels of MMP-2, ERK $1 / 2$, and MMP-9 in medium-dose propofol and HDPGs were significantly higher than those in control, fat emulsion and LDPGs $(p<0.05)$. The protein expressions of MMP-2, ERK1/2, and MMP-9 in high-dose propofol group were higher than values for MDPG $(p<0.05$; Table 3 and Figure 1).

Table 3: Effect of propofol on ERK1/2, MMP-2 and MMP-9 expressions in ovary cancer SKOV3 cell line

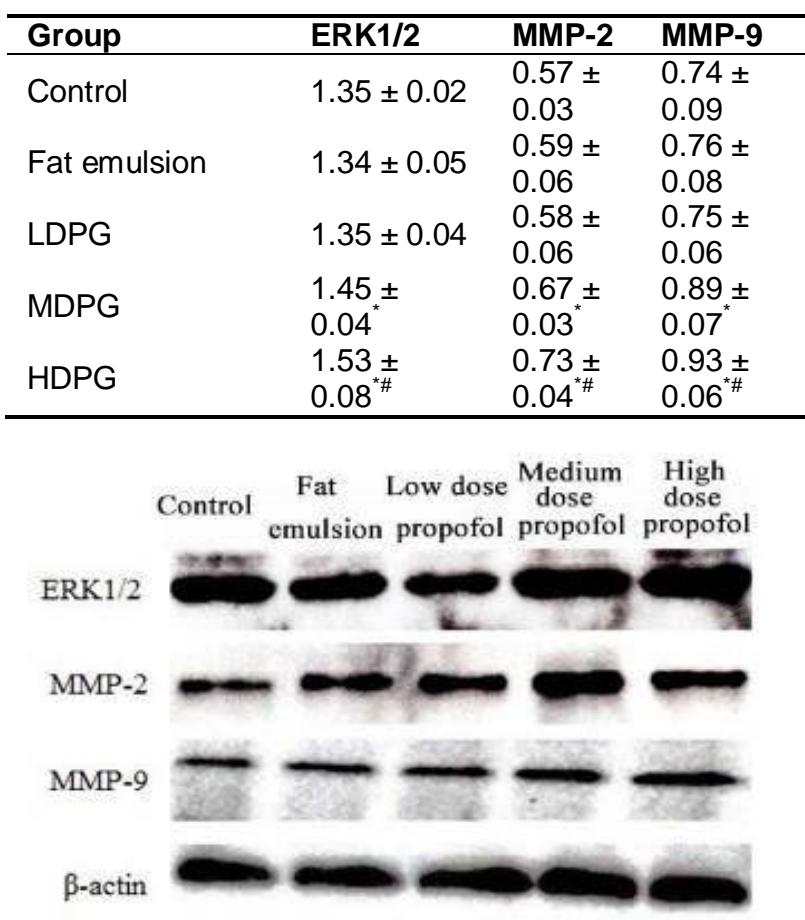

Figure 1: Effect of propofol on ERK1/2, MMP-2 and MMP-9 expressions in ovarian cancer SKOV3 cells

\section{Effect of propofol on the expressions of MMP-2 and MMP-9 in SKOV3 cells transfected with SiERK}

When compared with expression levels of MMP2 and MMP-9 in cells treated with siRNA, propofol was not effective in up-regulating these metalloproteinases in each treatment group. These results are shown in Figure 2 and Figure 3.

\section{DISCUSSION}

Surgery is still the best option for the treatment of most malignant tumors, with anesthesia as the key link between surgery and treatment.

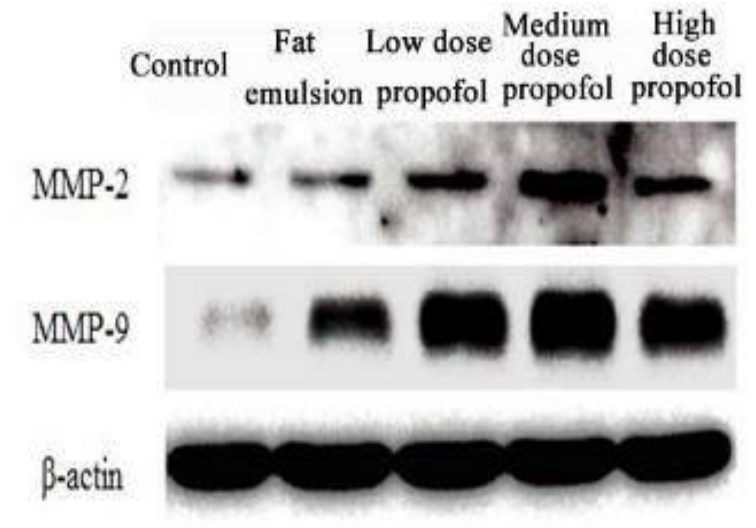

Figure 2: Effect of propofol on expressions of MMP-2 and MMP-9 in control si-RNA-transfected with cells

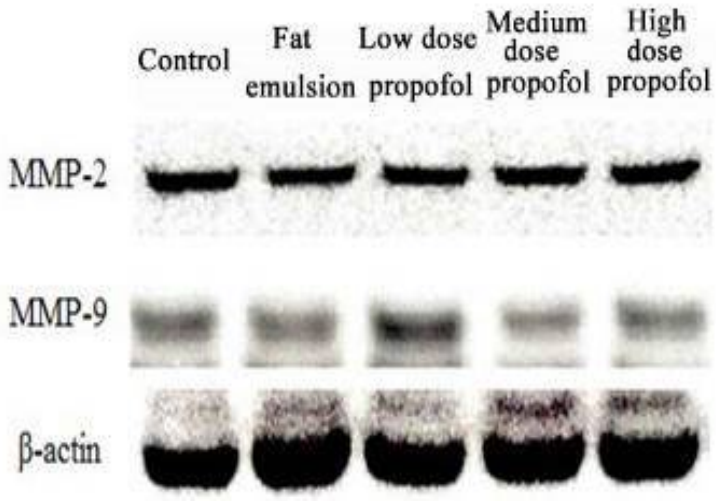

Figure 3: Effect of propofol on expressions of MMP-2 and MMP-9 in SKOV3 cells transfected with siERK

However, operation technique, immune function of the patient, invasion and proliferative capabilities of the tumor, and use of anesthetic medicament may promote recurrence of the tumor during the perioperative period. The inhibitory effect of anesthesia on immune function, and the direct effect of the anesthetic drugs on the tumor cells can affect the survival of the patients $[7,8]$.

Studies have shown that postoperative infection and tumor diffusion are closely related to the inhibitory effect of anesthesia on cellular immune function [9]. Some scholars have found that isoflurane inhalation promotes the proliferative and migratory abilities of tumor cells by upregulating the activity of tumor growth factors such as chemokine receptors [10]. In recent years, propofol, a popular drug used in radical operation of ovarian cancer, has attracted a lot of research interest with regard to its effect on the biological activities of tumor cells. It has been reported that propofol exerts different effects on the biological activities of various types of tumors [11]. For example, propofol decreases the expression of $\mathrm{Bcl}-2 / \mathrm{Bax}$ in rat $\mathrm{HCC}$ cells, thereby reducing their viability through enhanced

Trop J Pharm Res, February 2020; 19(2): 236 
apoptosis [12]. In this study, the influence of propofol on the biological behavior of ovarian cancer SKOV3 cell line was determined. It was found that propofol significantly enhanced the proliferative, migratory and invasive capacities of SKOV3 cells, and inhibited their apoptosis.

Tumor invasion and metastasis are a series of dynamic processes involving multi-factor interactions. The $E R K 1 / 2$ is an important molecule in signal transduction, and its biological function involves the transfer extracellular signals to cells, leading to a series of effects [13]. In recent years, it has been found that ERK1/2, which is widely present in a variety of cells, increases the proliferation and invasion of tumor cells after activation, and inhibits cell apoptosis [14]. Matrix metalloproteinases-2 and 3 are gelatinases belonging to matrix metalloproteinase family. High expressions of these enzymes accelerate the degradation of vascular basement membrane and extracellular matrix, and plays an important role in tumor invasion and metastasis [15]. Research has revealed that propofol decreases the proliferation of esophageal cancer cells through the ERK1/2VEGF signaling pathway [16].

In the present study, propofol markedly promoted the protein expressions of ERK1/2, MMP-2 and MMP-9 in a concentration-dependently. This suggests that the propofol-induced proliferative, migratory and invasive potential of SKOV3 cells are related to upregulation of the protein expressions of ERK1/2, MMP-2 and MMP-9. Earlier investigations have revealed that the ERK1/2 inhibitor suppresses the expression of MMP-2 in breast cancer cells dose-dependently, and it was presumed that MMP-2 and MMP-9 may be the downstream target genes of ERK1/2. In this study, after transfection of SKOV3 cells with siERK, it was found that expression levels of MMP-2 and MMP-9 were not effectively upregulated in each treatment group, which suggests that propofol might up-regulate the expressions of matrix metalloproteinases in SKOV3 cells by up-regulating ERK1/2.

\section{CONCLUSION}

Propofol enhances the proliferative, migratory and invasive potential of ovarian cancer cell SKOV3, and up-regulates the expressions of ERK1/2, MMP-2 and MMP-9 via a mechanism related to the activation of ERK1/2-MMP-2/9 signaling pathway. These may provide novel leads for development of new drugs for ovarian cancer.

\section{DECLARATIONS}

\section{Conflict of interest}

No conflict of interest is associated with this work.

\section{Contribution of authors}

We declare that this work was done by the author(s) named in this article and all liabilities pertaining to claims relating to the content of this article will be borne by the authors. All authors read and approved the manuscript for publication. Yasong Chi conceived and designed the study, Ruchang Yin, Chunyan Zhang, Aizhi Gen, Yanxiao Li, Hailei Yang, Xin Tian, Yasong Chi collected and analysed the data, while Ruchang Yin wrote the manuscript.

\section{Open Access}

This is an Open Access article that uses a funding model which does not charge readers or their institutions for access and distributed under the terms of the Creative Commons Attribution License (http://creativecommons.org/licenses/by/ 4.0) and the Budapest Open Access Initiative (http://www.budapestopenaccessinitiative.org/rea d), which permit unrestricted use, distribution, and reproduction in any medium, provided the original work is properly credited.

\section{REFERENCES}

1. Jacobs IJ, Menon U, Ryan A, Gentry-Maharaj A, Burnell M, Kalsi JK, Amso NN, Apostolidou S, Benjamin E, Cruickshank $D$, et al. Ovarian cancer screening and mortality in the UK Collaborative Trial of Ovarian Cancer Screening (UKCTOCS): a randomised controlled trial. Obstet Gynecol Surv 2016; 71(6): 346-348.

2. Knutson KL, Karyampudi L, Lamichhane P, Preston C. Retraction Note: Retraction note to: Targeted immune therapy of ovarian cancer. Cancer Metastasis Rev 2016; 35: 489-489.

3. Mills AM, Peres LC, Meiss A, Ring KL, Modesitt SC, Abbott SE, Alberg AJ, Bandera EV, Barnholtz-Sloan J, Bondy $M L$, et al. Targetable Immune Regulatory Molecule Expression in High-Grade Serous Ovarian Carcinomas in African American Women: A Study of $P D-L 1$ and IDO in 112 Cases from the African American Cancer Epidemiology Study (AACES). Int J Gynecol Pathol 2019; 38: 157-170.

4. Kim JH, Chang WP, Um D, Baek KH, Jo Y, An H, Kim Y, Kim TJ. Mass Spectrometric Screening of Ovarian Cancer with Serum Glycans. Dis Markers 2014; 2014: 634289. 
5. Gouda B, Gouda G, Borle A, Singh A, Sinha A, Singh $P M$. Safety of non-anesthesia provider administered propofol sedation in non-advanced gastrointestinal endoscopic procedures: A meta-analysis. Saudi J Gastroenterol 2017; 23: 133-143.

6. Kuhlmann L, Manton JH, Heyse B, Vereecke HE, Lipping $T$, Struys MM, Liley DT. Tracking Electroencephalographic Changes Using Distributions of Linear Models: Application to Propofol-Based Depth of Anesthesia Monitoring. IEEE Trans Biomed Eng 2017; 64(4): 870881.

7. Natanzon Y, Goode EL, Cunningham JM. Epigenetics in Ovarian Cancer. Semin Cancer Biol 2018; 51: 160-169.

8. Pal MK, Jaiswar SP, Dwivedi VN, Tripathi AK, Dwivedi A, Sankhwar P. MicroRNA: a new and promising potential biomarker for diagnosis and prognosis of ovarian cancer. Cancer Biol Med 2015; 12: 328-341.

9. Wright AA, Bohlke K, Armstrong DK, Bookman MA, Cliby WA, Coleman RL, Dizon DS, Kash JJ, Meyer LA, Moore $K N$, et al. Neoadjuvant Chemotherapy for Newly Diagnosed, Advanced Ovarian Cancer, Society of Gynecologic Oncology and American Society of Clinical Oncology Clinical Practice Guideline. Gynecol Oncol 2016; 143: 3-15.

10. Sintavanuruk K, Pongruekdee S, Thaharavanich $R$, Laosuwan S, Charuluxananan S. Comparative study of effective-site target controlled infusion with standard bolus induction of propofol for laryngeal mask airway insertion. J Biol Chem 2018; 4(1): 177-182.
11. Sneyd JR. Making sense of propofol sedation for endoscopy. Br J Anaesth 2017; 118(1): 6-7.

12. Kamal K, Asthana U, Bansal T, Dureja J, Ahlawat G, Kapoor S. Evaluation of efficacy of dexmedetomidine versus propofol for sedation in children undergoing magnetic resonance imaging. Saudi J Anaesth 2017; 11: 163-168.

13. Bae K, Park KE, Han J, Kim J, Kim K, Yoon KA. Mitotic cell death caused by follistatin-like 1 inhibition is associated with up-regulated Bim by inactivated Erk1/2 in human lung cancer cells. Oncotarget 2016; 7: 1807618084.

14. Cao R, Meng Z, Liu T, Wang G, Qian G, Cao T, Guan X, Dan $H$, Xiao $Y$, Wang $X$. Decreased TRPM7 inhibits activities and induces apoptosis of bladder cancer cells via ERK1/2 pathway. Oncotarget 2016; 7: 72941-72960.

15. Chen G, Yue Y, Qin J, Xiao X, Ren Q, Xiao B. Plumbagin suppresses the migration and invasion of glioma cells via downregulation of MMP-2/9 expression and inaction of PI3K/Akt signaling pathway invitro. J Pharmacol Sci 2017; 134(1): 59-67.

16. Thornton KJ, Kamangasollo E, White ME, Dayton WR. Active $G$ protein-coupled receptors (GPCR), matrix metalloproteinases 2/9 (MMP2/9), heparin-binding epidermal growth factor (hbEGF), epidermal growth factor receptor (EGFR), erbB2, and insulin-like growth factor 1 receptor (IGF-1R) are necessary for trenbol. $J$ Anim Sci 2016; 94: 2332-2343. 